\title{
Flame Structure, Spectroscopy and Emissions Quantification of Rapeseed Biodiesel under Model Gas Turbine Conditions
}

Cheng Tung Chong ${ }^{a^{*}}$ and Simone Hochgreb ${ }^{\mathrm{b}}$

${ }^{a}$ Faculty of Mechanical Engineering, Universiti Teknologi Malaysia, 81310 Skudai, Johor, Malaysia.

${ }^{\mathrm{b}}$ Department of Engineering, University of Cambridge, Trumpington Street, CB2 1PZ Cambridge, UK.

\begin{abstract}
The spray combustion characteristics of rapeseed biodiesel/methyl esters (RME) and 50\% RME/diesel blend were investigated and compared with conventional diesel fuel, using a model swirl flame burner. The detailed database with well-characterized boundary conditions can be used as validation targets for flame modelling. An airblast, swirl-atomized liquid fuel spray was surrounded by air preheated to $350{ }^{\circ} \mathrm{C}$ at atmospheric pressure. The reacting droplet distribution within the flame was determined using phase Doppler particle anemometry. For both diesel and RME, peak droplet concentrations are found on the outside of the flame region, with large droplets migrating to the outside via swirl, and smaller droplets located around the centreline region. However, droplet concentrations and sizes are larger for RME, indicating a longer droplet evaporation timescale. This delayed droplet vaporization leads to a different reaction zone relative to diesel, with an extended core reaction, In spite of the longer reaction zone, RME flames displayed no sign of visible soot radiation, unlike the case of diesel spray flame. Blending 50\% RME with diesel results in significant reduction in soot radiation. Finally, RME emits $22 \%$ on average lower $\mathrm{NO}_{\mathrm{x}}$ emissions compared to diesel under lean burning conditions.
\end{abstract}

Keywords: rapeseed, biodiesel, spray flame, spectroscopy, $\mathrm{CH}^{*}$ chemiluminescence

*Corresponding author

Address: Faculty of Mechanical Engineering Universiti Teknologi Malaysia 81310 Skudai Johor Darul Ta'zim Malaysia

Email: ctchong@mail.fkm.utm.my

Phone: +60(7) 5534631 ; $\quad$ Fax: +60 (7) 5566159

This paper was presented at the 7th International Conference on Applied Energy (ICAE2015), March 28-31, 2015, Abu Dhabi, UAE (Original paper title: "Fundamental Spray Combustion

Characteristics of Rapeseed Biodiesel, Diesel and Blend" and Paper No.: 484). 
Accepted for publication in Applied Energy 2 January 2016. Please cite as: Chong, C.T., Hochgreb, S., 2015. Flame structure, spectroscopy and emissions quantification of rapeseed biodiesel under model gas turbine conditions. Appl. Energy.(2015), vol. 8(2), 1383-1392. http://dx.doi.org/10.1016/j.apenergy.2016.01.003 


\section{Introduction}

The requirement to meet stringent environmental legislation and emissions targets has prompted continuous development for clean, sustainable alternative fuel and low emissions combustion technology. In the field of gas turbine, fuel flexibility is a desirable feature from the standpoint of meeting emissions goal and reducing operating cost. One of the prospective alternative fuels for gas turbine is biodiesel. Renewable biodiesel has emerged as a potential fuel offering low carbon and pollutant emissions. Derived from biomass or animal fats, biodiesel (also known as fatty acid methyl esters, or FAME) comprises of a mixture of long chain methyl esters with physical properties comparable to that of conventional diesel fuel. Due to its proven feasibility as substitute fuel or as blend with diesel in compression-ignition engines $[1,2]$, further application of biodiesel in stationary applications such as boiler, furnaces and gas turbines system is envisaged. Prior studies have only considered the effect of FAME fuels on emissions, yet these differences cannot be easily explained without details on the flame structure in continuous flow devices. The present work shows detailed information on the structure of the sprays for well-defined boundary conditions, providing a suitable validation target for modellers, as demonstrated in [3].

Fundamental combustion characteristics and performance of biodiesel have been studied using model gas turbine burner by several groups. Hashimoto et al. [4, 5] investigated the operation of palm and jatropha biodiesel in a liquid swirl flame gas turbine burner, showing that larger biodiesel droplets were generated compared to the baseline diesel fuel. The radiation intensity and soot emissions were reported to become lower with increasing fractions of biodiesel. Measured carbon monoxide emissions for jatropha spray flames were found to be higher than those of diesel fuels at low flame temperatures $\left(<1300^{\circ} \mathrm{C}\right)$ due to low fuel volatility, with similar $\mathrm{NO}_{\mathrm{x}}$ emission levels. Palm biodiesel showed lower $\mathrm{NOx}$ emissions level compared to baseline diesel. The lower NOx emission result concurs with the finding 
shown by Chong and Hochgreb [6] despite differences in spray burner geometry and operating conditions. Hashimoto et al. utilised a pressure-swirl injector while Chong and Hochgreb used an airblast injector for fuel atomization. The latter performed detailed spatial droplet measurement within the flame and extensively characterised the burner flow field under reacting and non-reacting conditions to provide data for flame modelling [7]. Sequera et al. [8] Panchasara et al. [9] utilised an airblast-injector type axial swirl combustor to compare the emissions of soy methyl ester, soy ethyl ester, bio-oil pyrolised from hardwood and chicken fat-based biodiesels against diesel fuel. The result showed lower emissions for both $\mathrm{NO}_{\mathrm{x}}$ and $\mathrm{CO}$ for biodiesel-blended fuels. Erazo Jr. et. al. [10] reported similar lower NO and CO emission trend for canola oil spray flame compared to diesel. Droplet measurement showed that canola oil spray was finer compared to diesel under reacting conditions, contrary to larger droplet size for biofuels as reported by others $[5,6]$. These results showed that biodiesel quality is feedstock dependent and has significant impact on spray atomization and emissions.

The use of biodiesel to micro gas turbine has been shown feasible by several groups. Using the same $30 \mathrm{~kW}$ micro gas turbine (MGT) engine (Capstone C30), four different studies found three different kinds of behaviour. Krishna [11] and Habib et al. [12] reported lower $\mathrm{CO}$ and $\mathrm{NO}$ emissions for soy and other vegetable biodiesel blends compared to diesel, whereas Bolszo and McDonell [13] reported higher $\mathrm{NO}_{\mathrm{x}}$ emissions for a soy-based biodiesel attributable to longer evaporation timescale. Chrieallo et al. [14] found emission levels unchanged for blends of rapeseed and sunflower oil compared to neat Jet-A1. In contrast, Chiaramonti et al. [15] found that $\mathrm{CO}$ emissions could be higher for biodiesels (vegetable oil, biodiesel, vegetable oil/biodiesel blend) than oils in a Garrett GTP 30-67 liquid fuel MGT engine. Rehman et al. [16] compared the emission performance of jatropha/diesel blends against diesel fuel in a $44 \mathrm{~kW}$ (IS/60 Rovers) gas turbine test. Contrary to the result 
shown by Hashimoto et al. [4], jatropha biodiesel-diesel blends led to reduced emissions of $\mathrm{CO}$ and unburned hydrocarbons, but higher $\mathrm{NO}_{\mathrm{x}}$ emissions. Nascimento et al. [17] reported an increase in $\mathrm{CO}$ and decrease of $\mathrm{NO}$ emissions for castor biodiesel and castor biodiesel/diesel blends under MGT at full and partial operational load. The same trend of $\mathrm{CO}$ and NO emissions was reported for crude rapeseed oil testing conducted in a MGT [18]. For biomassderived butanol and butanol/Jet-A blends, lower $\mathrm{CO}$ and $\mathrm{NO}$ emissions were observed in a MGT test conducted by Mendez et al. [19]. Most of the above-mentioned MGT studies did not characterise the spray and droplets under reacting condition which could be one of the important factors affecting final emissions.

The applicability of biodiesel in industry scale gas turbine engine has been demonstrated by Molière et al. [20] in a 40 MW gas turbine field test using rapeseed methyl esters. The test results showed lower $\mathrm{NO}_{\mathrm{x}}$ emission compared to diesel. Purcher et al. [21] operated an industrial gas turbine sector rig (Allison/Rolls Royce T56-A-15 combustion systems) fuelled with biodiesel blends derived from vegetable oil, canola oil, fish oil and biooil with Jet-A1 to study the exhaust emissions. Higher hydrocarbon emissions were observed for biodiesel blends compared to baseline Jet-A1. Timko et al. [22] tested $20 \%$ and $40 \%$ blends of biodiesel with Jet-A1 fuel in an actual aviation gas turbine engine (CFM56-7B turbo-fan engine). Post-combustion emissions showed a reduction of $\mathrm{NO}_{\mathrm{x}}$ and $\mathrm{CO}$ emissions biodiesel blends. The effect of blending biodiesel with JP-8 fuel was investigated in a helicopter turboshaft engine (T63-A-700) [23]. Particulate matter emissions was reduced by $15 \%$ for $20 \%$ biodiesel blend relative to baseline but other gaseous emissions were similar.

The conflicting biodiesel performance and emission trends in the gas turbine literature is not surprising, considering the differences in fuel rheology, combustion chamber geometries and operating conditions that could affect overall combustion performance. In addition, variations in biodiesel composition and quality depending on feedstock type can add 
to the inconsistency. The complex nature of swirl flames involves interaction between spray atomization, flow field and reactions, requiring thorough characterisation to ensure effective atomization and combustion. The present experiment focuses on the investigation of spray combustion characteristics of rapeseed methyl esters (RME) and 50\% RME/diesel blends using an axial swirl model gas turbine burner, with emphasis on the examination of spray flame structures, spectroscopy, reacting droplet characteristics and emissions under globally lean, continuous swirl reacting conditions. Unlike the previous studies on rapeseed biodiesel combustion $[17,20]$, the present study aims to elucidate the fundamental combustion properties rapeseed under swirling spray condition and to provide a detailed database of rapeseed spray flame with well-defined geometry suitable for reacting flame modelling.

\section{Experimental}

\subsection{Burner system}

A single annulus, axial swirl gas turbine type burner was employed to establish liquid spray flame under steady state condition. A commercial twin-fluid atomizer (Delavan: SN type-30610-1) was utilised to atomize liquid fuel prior to mixing with main swirling air. The atomizing air and fuel orifice diameters of the atomizer are 1.73 and $0.50 \mathrm{~mm}$ respectively. The axial swirler consists of eight straight vanes positioned at $45^{\circ}$ from the axial centreline axis. The swirl number of the axial swirler is estimated to be $S_{N} \sim 0.78$, which is sufficiently strong $\left(S_{N}>0.6\right)$ to generate recirculation flow with high intensity to assist flame stabilisation [24]. The swirler was placed concentrically with the atomizer at the burner outlet. A circular quartz tube with a diameter of $100 \mathrm{~mm}$ and $180 \mathrm{~mm}$ in length was used to form a combustor wall at the burner outlet, while one end of the tube was exposed to open atmospheric condition. Details of the burner geometry are shown in Table 1.

The liquid and gas flows were supplied independently to the atomizer. The atomizing air and fuel were supplied through a thermal-type (Bronkhorst: F-203AV $; \pm 1 \%$ full scale (FS) 
accuracy) and Coriolis-type (Bronkhorst: M13 mini CORI-FLOW; $\pm 0.4 \%$ FS accuracy) mass flow controllers (MFCs). Airblast atomization was achieved via the impingement of highvelocity atomizing air on the liquid jet at the atomizer outlet. The main swirling air flow, supplied to the burner plenum by using a thermal-type MFC (Bronkhorst: F-201AV; $\pm 1 \%$ FS accuracy), envelops the atomized spray droplets to form a combustible mixture prior to ignition. The main air flow was preheated using two in-line air heaters (RS: 200-2547: 750 $\mathrm{W} /$ heater) arranged in series to elevated temperature of $350{ }^{\circ} \mathrm{C}$. Three rope heaters (Omega: FGR-100-240V, $500 \mathrm{~W} /$ rope) were used to heat the burner plenum and body. The burner was insulated with high temperature, heat resistant ceramic wool to reduce heat loss. A $1.5 \mathrm{~mm}$ thermocouple was positioned $10 \mathrm{~mm}$ upstream of the burner to measure the temperature of the preheated main air flow, apart from providing a signal feedback to the PID controller to control heating elements. The uncertainty in the temperature associated with the preheated air is within $\pm 5 \mathrm{~K}$. Schematic of the burner and flow delivery system is shown in Fig. 1a, while the placement position of swirler at the burner outlet is shown in Fig. $1 b$.

\subsection{Fuels tested}

The present rapeseed biodiesel/methyl esters (RME) supplied by ADM International Sarl conforms to the European Union's EN14214 standard. Rapeseed biodiesel comprises of a mixture of methyl esters, typically $64.1 \%$ methyl oleate, $22.5 \%$ methyl linoleate, $8 \%$ methyl linolenate and $3.5 \%$ methyl palmitate by weight [25], which constitutes approximately $87 \%$ unsaturated methyl esters due to the presence of double bond in the molecules. The commercial grade low sulphur diesel fuel was obtained from a local petrol kiosk in the UK. The typical composition of diesel fuel is $25-50 \%$ of paraffins, $20-40 \%$ of cycloparaffins and 15-40\% of aromatics [26]. A gas chromatographic elution profile (D5 type column: Supelco 
SLM-5ms) is shown in Fig. 2. The complex diesel fuel comprises of a wide spectrum of hydrocarbons, while RME exhibits a relatively simple composition of one dominant peak and several satellite peaks.

Due to the inherent presence of oxygen in biodiesels, the energy content of RME is lower than diesel [27]. Table 2 shows the fuel physical properties of RME and diesel. The heating value of RME is lower than that of diesel by $17 \%$ on a mass basis, but only by $12 \%$ lower on a volume basis, due to the higher mass density. RME has slightly higher viscosity and flash point compared to diesel. Ultimate analyses shows that RME contains oxygen, with $\mathrm{C} / \mathrm{O}$ ratio of 10.06 despite the rather similar $\mathrm{H} / \mathrm{C}$ ratio as diesel. Blending of $\mathrm{RME}$ with diesel for this experiment was performed at 50\% volumetrically. The physical properties of the blend, including the density, lower heating, and molecular weight values are estimated based on Kay's mixing rules $\phi=\sum x_{i} \phi_{i}$, where $\phi$ is the property of the blend, $\phi_{i}$ is the respective property of the $i^{\text {th }}$ component and $x_{\mathrm{i}}$ is the mass fraction of the $i^{\text {th }}$ component [28].

\subsection{Operating conditions}

The main bulk swirling air was preheated to a temperature of $350{ }^{\circ} \mathrm{C}$ prior to introduction into the burner and mixing with the liquid fuel spray. The atomizing air and liquid fuel were delivered independently at room temperature to the burner outlet at the fixed atomizing air-to-fuel mass ratio (ALR) of 2, at which good atomization can be achieved. Detailed characterisation of non-reacting spray using the present internal-mix twin-fluid atomizer has been shown in previous work [29]. The established flames were compared at the same burner power output of $6 \mathrm{~kW}$ and globally lean condition of $\phi=0.47$ at atmospheric condition. The operating conditions for the fuels tested are shown in Table 3. 


\subsection{Measurement techniques}

\subsubsection{Flame imaging and emission spectroscopy}

Imaging of the global flame reaction zone of spray flames was performed by using an intensified charged-coupled device (CCD) camera (LaVision; IRO Image Intensifier, Imager Pro X 4M). The spectral range of the CCD camera is 290-1100 nm. A UV lens was used with a bandpass filter centered at 430 $\pm 10 \mathrm{~nm}$ (Thorlabs; FB430-10) for $\mathrm{CH}^{*}$ chemiluminescence imaging of the main heat reaction zone. The excited $\mathrm{CH}^{*}$ chemiluminescence from the flames is indicative of the heat release rate [30]. The gain of the intensifier for $\mathrm{CH}^{*}$ chemiluminescence was set to $80 \%$ with a gate delay time of $80000 \mathrm{~ns}$. The peak transmission rate of the bandpass filter (FB430-10) is approximately 45\%. The spray flame images were captured via direct line-of-sight imaging through the transparent quartz tube.

For the imaging of post-reaction flame structures, a $60 \mathrm{~mm} / \mathrm{F} 5.6$ Nikkor lens fitted with a long bandpass filter (Thorlab; FEL0500) with the cutoff wavelength of $>550 \mathrm{~nm}$ was used with the CCD camera (La Vision; Imager Pro X 4M). The peak transmission rate of the broadband filter is $80 \%(400-700 \mathrm{~nm})$ and $75 \%(750-1000 \mathrm{~nm})$.

A spectrometer (Ocean Optics: USB2000+) was utilised to spectrally resolve the radiation intensity from the UV to near infrared range $(200-900 \mathrm{~nm})$. The signals from the flames were focused onto the slit of the spectrometer. The time-averaged spectra were obtained with an integration time of $1 \mathrm{~s}$ and the signal-to-noise ratio of $>10$.

\subsubsection{Reacting droplets characterisation}

Measurements of the reacting droplet velocity and size distributions in a swirl flame were performed using a one-dimensional non-intrusive phase Doppler anemometry (PDA) 
(Dantec: 112 mm Fiber PDA). The PDA system consists of a continuous Argon-ion laser (Coherent: Innova 70C) that produces continuous laser beam at $514.5 \mathrm{~nm}$. The beam transmitter splits the laser beam into 2 to form a measurement volume intersecting at the focal length of $500 \mathrm{~nm}$. Droplets passing through the measurement volume reflect light signals that are captured by the receiving optics in forward scattering mode. The receiving optics with a focal length of $310 \mathrm{~nm}$ were positioned at the scattering angle of $56^{\circ}$ off axis. The transmitting and receiving optics were placed on 3-directional traverse system that allows spatial translation of the measurement volume within the flame to within the accuracy of $\pm 0.1 \mathrm{~mm}$. Measurements of droplet characteristics were performed at $\mathrm{z}=10,15$ and $20 \mathrm{~mm}$ downstream of burner outlet. The statistical uncertainty is estimated to be $\pm 2 \%$ for the droplet velocity and $\pm 5 \%$ for diameters. Detailed setting and parameters of the beam transmitter and receiving optics for the PDA system is shown in Table 4.

\subsubsection{Emissions measurements}

The post-combustion emissions of $\mathrm{NO}, \mathrm{NO}_{2}$ and $\mathrm{CO}$ were measured using a gas analyzer (Tocsin 320) at the combustor outlet. The sampling probe was placed $10 \mathrm{~mm}$ inward from the combustor outlet to sample across the burner exit. The inlet diameter of the sampling tube is $4 \mathrm{~mm}$ and the sampling gas volume is around $6 \mathrm{~L} / \mathrm{min}$. The sampling line was heated to the temperature of $180{ }^{\circ} \mathrm{C}$ and insulated to prevent condensation of post-combustion products. The gas analyzer was calibrated using calibration gases prior to measurements.

\section{Results and discussion}

\section{1 $\mathrm{CH}^{*}$ chemiluminescence and long bandpass $(>550 \mathrm{~nm})$ imaging}


The obtained line-of-sight planar flame images of $\mathrm{CH}^{*}$ chemiluminescence were averaged (300 images) and deconvoluted via Abel transformation to obtain the planar flame structures. Figure 3a-c show the planar flame structures of diesel, 50\% RME/diesel and RME swirl flames respectively. Diesel and the 50\% RME/diesel blend show similar reaction zones, with the bulk of the heat release arising on the inner side of the velocity shear layer. For the RME flame (Fig. 3c), heat release takes place in a heart-shape high intensity region that is slightly larger than that of diesel. We note that the interpretation of $\mathrm{CH}^{*}$ chemiluminescence is significantly dependent on the type of fuel as well as on the local equivalence ratio, which is variable in space depending on the extent of mixing at the flame zone. Nevertheless, the higher centrally located intense flame exhibited by RME may be possibly attributed to the effect of fuel physical properties of lower volatility and higher surface tension that delay the droplet vaporisation rate, thus extending the reaction rate further along the axis. The length of the main reaction zones for all tested fuels was confined to within $30 \mathrm{~mm}$ from burner outlet, beyond which, no significant heat release takes place.

Comparison of the half-plane radial $\mathrm{CH}^{*}$ chemiluminescence intensity profiles at $\mathrm{z}=5$, 10 and $15 \mathrm{~mm}$ from the burner outlet are presented in Fig. 3d-f. The abscissa indicates the radial profile from the centreline $(\mathrm{x}=0 \mathrm{~mm})$ of the burner. Diesel flame shows high $\mathrm{CH}^{*}$ intensity peak at axial profile of $5 \mathrm{~mm}$. The $\mathrm{CH}^{*}$ intensity reduces further downstream towards 10-15 mm. Similar trends were observed for the 50\% RME/diesel blends. However, RME flame $\mathrm{CH}^{*}$ profiles are higher at $10 \mathrm{~mm}$ than at $5 \mathrm{~mm}$. The axial profiles at $15 \mathrm{~mm}$ is also higher than diesel and blend. The high $\mathrm{CH}^{*}$ intensity profiles at 10 and $15 \mathrm{~mm}$ for RME is attributed to the delayed vaporisation of droplets that shifted the location of main heat reaction zone. The delayed vaporisation of RME droplet is reflected in the relatively higher droplet number density at all axial locations compared to baseline as shown in section 3.3. 
Imaging of the long wavelength $(>550 \mathrm{~nm})$ region shows the radiation from RME spray flame (Fig. 4c) is significantly different than that of the diesel flame (Fig. 4a). The main difference between fuels is the very large luminous region arising from the presence of soot in the diesel flame relative to the other fuels. For RME, the post-reaction zone is much less luminous downstream of the flame, indicative a low level of soot formation. Interestingly, the blend of 50\% RME with diesel shows a much lower luminosity than would be expected from a proportional effect. Instead, the flame structure is similar to the pure RME flame with low signal intensity emitted at the post-reaction zone. The absence of soot in RME/diesel blend can be attributed to the presence of oxygen molecule in the fuel that allows fast oxidation of soot precursor and thus inhibits the formation of soot, as has been observed by others $[31,32]$.

Comparison of the half-plane longpass signals $(>550 \mathrm{~nm})$ intensity profiles at $\mathrm{z}=10,20$, $30 \mathrm{~mm}$ downstream of burner outlet for the fuels tested are shown in Fig 4d-f. The high luminosity of the post reaction zone region for diesel flame is reflected in the high intensity count as a result of soot radiation. Compared to the cases with $50 \% \mathrm{RME} /$ diesel blend and RME, the intensity counts for diesel are higher by a factor of 3, especially further downstream. RME shows no such sooting tendency, with very low emission in this spectral region. The $50 \% \mathrm{RME} /$ diesel blend shows similar intensity profiles as RME, indicating the absence of soot at post reaction zone region.

\subsection{Global flame emission spectra}

The global flame spectra obtained from the tested fuels are shown in Figure 5. The diesel flame presents a prominent broadband spectrum between 550 to $850 \mathrm{~nm}$ due to the intense luminosity radiated by soot, corresponding to yellow-orange colour spectrum as was observed in the flame. In contrast, RME flame shows essentially no soot luminosity within the 
wavelength band of 580 and $900 \mathrm{~nm}$. Instead, a single distinct peak located at $588 \mathrm{~nm}$ was observed from the RME flame radiation, which explains the orange-reddish flame brush. The radiation at $588 \mathrm{~nm}$ is not due to soot, but instead from the trace inorganic material sodium, which is known to be present in biodiesel. The 50\% RME/diesel blend exhibits spectral characteristics similar to RME. Despite the presence of aromatics in diesel, the blend shows no sign of soot, as indicated by the absence of soot band (580-900 nm). This can be attributed to the role of oxygen in the fuel, which interferes with the formation of double carbon bonds and eventually the formation in soot.

\subsection{Spray droplet size and volume flux characterisation}

The droplet number density profiles of the spray flames are shown in Fig. 6a-c. Measurements were made at the axial positions of $\mathrm{z}=10,15$ and $20 \mathrm{~mm}$ from the burner outlet, where there are sufficient numbers of droplets. The droplet concentrations are consistent with a hollow cone distribution, with peaks in droplet concentrations over an angle which opens up as a function of distance [33]. The droplet concentrations drop very rapidly, by an order of magnitude every $5 \mathrm{~mm}$. The low droplet density within the spray inner core is due to the intense convective evaporation by the hot gases that rapidly consumes the droplets. This is evident when compared to a previous non-reacting spray study where droplet concentrations in the center region is significant [29]. The droplet concentrations for RME are highest, followed by that of the blend, which is close to that of diesel. At $\mathrm{z}=10 \mathrm{~mm}$, the peak RME droplet concentrations are higher by a factor of 2 compared to those of diesel and $50 \%$ RME/diesel blend. Further downstream of $\mathrm{z}=15 \mathrm{~mm}$, the overall droplet number density is reduced by a factor of 10 . 
The corresponding radial distribution of droplet volume flux profiles (Fig. 6d-f) shows a similar trend as the droplet number density profiles, now weighted by the differences in droplet volume and velocity. The peak volume flux and concentrations move from a radial distance around $6 \mathrm{~mm}$ at $10 \mathrm{~mm}$ axial distance to $9 \mathrm{~mm}$ at $20 \mathrm{~mm}$ axial distance, forming a concentrated angle of around 11 degrees from the centreline axis. The region of high droplet number density and fluxes coincides with the locations of intense chemiluminescence (Fig. 3): this indicates that the peak heat release rate must be close to the regions with sufficiently high fuel concentrations. The consistently high droplet density and volume flux for the RME flame is partly due to the higher fuel mass flow rate by $17 \%$ compared the diesel under the present constant power output condition, and the slower evaporation rate of biodiesel due to its lower volatility, higher boiling point and higher surface tension.

The droplet axial velocity distribution in the flames considered is shown in Fig. 7a-c. In general, peak droplet velocities exhibited by all fuel types are substantially higher than the local gas velocities measured previously, as the momentum is created by the spray itself. Quantification of the gas velocity within the combustor under reacting conditions with spray has been reported in Ref. [7]. Measurement of the diesel spray flame flow field under the exact same operating conditions as the present diesel spay flame showed a reverse flow at the combustor centreline region induced by the recirculation zone. This reverse velocity creates a net downstream drag force on the droplets, which affects the spray droplet distribution. The spray velocity pattern is consistent with the behavior of a hollow spray, with peaks along an expanding cone, which spreads out away from the origin into a broader peak as the spray disperses and exchanges momentum with the surrounding recirculation zone. Only marginal differences were observed between the droplet velocities profiles between the fuels tested. The differences in droplet velocity become more pronounced at the downstream location of 
$20 \mathrm{~mm}$, where the velocities for RME and 50\% RME/diesel blend are slightly higher than diesel, owing to the higher momentum sustained by the surviving droplets.

The corresponding droplet size distribution is shown in Fig. 7d-f. In general, droplet Sauter mean diameter (SMD) increases with radial distance as the larger droplets leaving the swirling spray tip have higher momentum and therefore penetrate farther than smaller droplets Further away from the spray origin, the droplet size decreases by evaporation and reaction, leaving a cloud of more uniform droplets. At $20 \mathrm{~mm}$ from the burner exit, small droplets in the centreline region disappear. There are only modest differences between droplet diameters for different fuel types. RME shows slightly larger droplets than diesel, and the blend droplet behaviour is closer to that of diesel.

There is often an inverse correlation between droplet velocity and diameter in air blast injectors [34]: small droplets are carried by the fast air velocity, whilst large droplets are slowed down by drag. The droplet velocity-size relations for diesel and RME reacting sprays are shown in Fig $8 \mathrm{a}$ and $8 \mathrm{~b}$ respectively. Smaller droplets $(<20 \mu \mathrm{m})$ that survive before complete vaporization attain high velocity $(>40 \mathrm{~m} / \mathrm{s})$ due to the high momentum from the air blast air. Larger droplets are centrifuged out to the outer radii, where the velocities quickly decrease at the spray edges. The overall larger droplet size of RME within the flame is reflected in a more disperse plot with a wider range of velocity and size at all axial locations, as opposed to diesel. 


\subsection{Emissions performance}

The emission indices (expressed in per unit $\mathrm{kg}$ of fuel and $\mathrm{kWh}$ ) of $\mathrm{NO}, \mathrm{NO}_{2}$ and $\mathrm{CO}$ expressed as a function of excess air ratio under the same power output conditions are shown in Fig. 9. The excess air ratio is defined as $\lambda=\left(\mathrm{AFR} / \mathrm{AFR}_{s}\right)-1$, where $\mathrm{AFR}$ is the air fuel ratio and the subscript $s$ indicates stoichiometric. NO emissions for all fuels peak between 0.5 and 1.0 excess air ratio, and for RME, at about 1.5 . One would generally expect a decrease from stoichiometric based on a purely thermal effect. The peak in the lean region indicates that both vaporization and incomplete mixing play a role. RME shows lower $\mathrm{NO}$ and $\mathrm{NO}_{2}$ emissions compared to diesel or the blend, particularly near the stoichiometric region. Since the adiabatic temperatures in this region are similar (around $2560-2580 \mathrm{~K}$ ), and the power is kept constant, the lower NO values per unit fuel must be attributed in part to the higher heat of vaporization of the RME spray, but it could also be via presence of oxygen in the fuel, and the consequent partial suppression of part of the prompt NO formation mechanism. The differences between fuels disappear by excess ratio 2.3. $\mathrm{NO}_{2}$ emissions are lower by an order of magnitude compared to $\mathrm{NO}$. The reduction in $\mathrm{NO}_{2}$ with excess air ratio follows that of $\mathrm{NO}$, since $\mathrm{NO}_{2}$ is formed from the resulting NO. The $50 \% \mathrm{RME} /$ diesel blend behaves in a similar manner to the pure diesel fuel with respect to NO, which shows the very non-linear contribution of fuel type.

$\mathrm{CO}$ emissions are practically identical for all fuels, with a minimum at excess air ratio of unity (equivalent to an equivalence ratio of one half). For low excess air ratios, too many rich pockets survive, and $\mathrm{CO}$ emissions are higher. For high excess ratios, the temperatures are very low, and any $\mathrm{CO}$ formed in rich spray pockets are quenched by the low temperature mixture, preventing re-burning, as well as the shorter reaction time given the higher mass 
flow rates. The lowest $\mathrm{CO}$ emissions appear for the optimum point where there is sufficient mixing of fuel and air, yet the temperatures are not too low.

The emission results for $\mathrm{NO}, \mathrm{NO}_{2}$ and $\mathrm{CO}$ are shown in Fig. 10 as a function of atomizing air-to-liquid ratio (ALR). Comparison of emissions are performed under the same burner power output of $6 \mathrm{~kW}$ and a fixed $\mathrm{AFR}=32$, so that the behavior reflects the influence of the atomizing air only. Emissions of $\mathrm{NO}$ and $\mathrm{NO}_{2}$ emissions for $\mathrm{RME}$ are generally lower than those of diesel at these conditions, reflecting the lower adiabatic temperatures. The sensitivity of $\mathrm{NO}$ and $\mathrm{NO}_{2}$ emissions to ALR is similar for all fuels, reflecting the first order effect of lowering the bulk adiabatic temperatures by air addition. $\mathrm{CO}$ emission indices are slightly higher for RME relative to the other fuels - this is most likely a results of the lower adiabatic temperatures and larger droplet sizes, both of which slow down the completion of reaction.

\section{Conclusion}

Comparison of the spray combustion characteristics of RME and 50\% RME/diesel blend was performed against diesel under the same burner power output of $6 \mathrm{~kW}$. All reaction zones appear similar as indicated via $\mathrm{CH}^{*}$ chemiluminescence, but are more concentrated for RME. RME flames are non-sooting, and there is very little soot in the blended fuel flame, showing that the soot reduction effect is very non-linear. Global measurements of the light emission spectra of the flames reveal that unlike the other fuels, RME produces a flame with a distinct peak at $588 \mathrm{~nm}$, which can be attributed to sodium in the fuel. The RME spray flame shows a higher volumetric density and flux of droplets, which is accounted for by the higher flux required to maintain the same power as the other fuels. Nevertheless, velocities are similar across all mixtures, with the RME spray droplets significantly larger than those of the other two fuels, revealing the role of the fuel physical properties, particularly surface tension 
and viscosity. Droplets distributed within the inner zone of the spray core are smaller relative to those located outside the boundaries of the flame, disappearing at the centre, where high temperatures promote rapid vaporisation. Emissions results under lean operating conditions show that emission indices for $\mathrm{NO}$ and $\mathrm{NO}_{2}$ for RME are consistently lower than diesel, which can be attributed primarily to the lower adiabatic temperatures produced. $\mathrm{CO}$ emissions are somewhat higher for RME owing to the lower temperatures produced, as well as the slower vaporization rate for the higher droplets. The overall result shows that RME exhibits potential as supplemental fuel for gas turbine, either as neat or blend with diesel in view of the marginal difference in global flame structure, improved NOx emissions and non-sooting characteristics. Quantitative measured data and the well-defined boundary conditions can be used as validation targets for computational flame modelling.

\section{Acknowledgement}

The financial support from the Ministry of Higher Education and Universiti Teknologi Malaysia (Research university matching grant vot no.: 00M45) and Ministry of Science, Technology and Innovation (MOSTI) Malaysia (vot no.: 03-01-06-KHAS01) is gratefully acknowledged.

[1] $\mathrm{Ng} \mathrm{J}, \mathrm{Ng} \mathrm{HK}$, and Gan $\mathrm{S}$, Characterisation of engine-out responses from a light-duty diesel engine fuelled with palm methyl ester (PME), Appl Energy 2012; 90:58-67.

[2] Macor A, Avella F, and Faedo D, Effects of 30\% v/v biodiesel/diesel fuel blend on regulated and unregulated pollutant eissions from diesel engines, Appl Energy 2011; 88:4989-5001.

[3] Mohd Yasin MF, Cant RS, Chong CT, and Hochgreb S, Discrete multicomponent model for biodiesel spray combustion simulation, Fuel 2014; 126:44-54.

[4] Hashimoto N, Nishida H, and Ozawa Y, Fundamental combustion characteristics of jatropha oil as alternative fuel for gas turbines, Fuel 2014; 126:194-201. 
[5] Hashimoto N, Ozawa Y, Mori N, Yuri I, and Hisamatsu T, Fundamental combustion characteristics of palm methyl ester (PME) as alternative fuel for gas turbines, Fuel 2008; 87:3373-3378.

[6] Chong CT and Hochgreb S, Spray combustion characteristics of palm biodiesel, Combust. Sci. Technol. 2012; 184:1093-1107.

[7] Chong CT and Hochgreb S, Measurements of Non-reacting and Reacting Flow Fields of a Liquid Swirl Flame Burner Chinese Journal of Mechanical Engineering 2015; 22:1-8.

[8] Sequera D, Agrawal AK, Spear SK, and Daly DT, Combustion performance of liquid biofuels in a swirl-stabilized burner, J. Eng. Gas Turb. Power 2008; 130:032810.1032810.10.

[9] Panchasara HV, Simmons BM, Agrawal AK, Spear SK, and Daly DT, Combustion Performance of Biodiesel and Diesel-Vegetable Oil Blends in a Simulated Gas Turbine Burner, Journal of Engineering for Gas Turbines and Power 2009; 131:031503.1-031503.11.

[10] Erazo Jr JA, Parthasarathy R, and Gollahalli S, Atomization and Combustion of canola methyl ester biofuel spray, Fuel 2010; 89:3735-3741.

[11] Krishna CR, "Performance of the capstone C30 microturbine on biodiesel blends," Brookhaven National Laboratory2007.

[12] Habib Z, Parthasarathy R, and Gollahalli S, Performance and emission characteristics of biofuel in a small-scale gas turbine engine, Appl. Energy 2010; 87:1701-1709.

[13] Bolszo CD and McDonell VG, Emissions optimization of a biodiesel fired gas turbine, Proc. Combust. Inst. 2009; 32:2949-2956.

[14] Chrieallo F, Allouis C, Raele F, and Massoli P, Gaseous and particulate emissions of a micro gas turbine fuelled by straight vegetable oil-kerosene blends, Exp. Thermal Fluid Sci. 2013;

[15] Chiaramonti D, Rizzo AM, Spadi A, Prussi M, Riccio G, and Martelli F, Exhaust emissions from liquid fuel micro gas turbine fed with diesel oil, biodiesel and vegetable oil, Appl Energy 2013; 101:349-356.

[16] Rehman A, Phalke DR, and Pandey R, Alternative fuel for gas turbine: Esterified jatropha oil-diesel blend, Renewable energy 2011; 36:2635-2640.

[17] Nascimento MAR, Lora ES, Correa PSP, Andrade RV, Rendon MA, Venturini OJ, et al., Biodiesel fuel in diesel micro-turbine engines: Modelling and experimental evaluation, Energy 2008; 2008:233-240.

[18] Kun-Balog A and Sztanko K, Reduction of pollutant emissions from a rapeseed oil fired micro gas turbine burner, Fuel Processing Tech 2015; 134:352-359.

[19] Mendez CJ, Parthasarathy R, and Gollahalli S, Performance and emission characteristics of butanol/Jet A blends in gas turbine engine, Appl Energy 2014; 118:135-140.

[20] Molière M, Panarotto E, Aboujaib M, Bisseaud JM, Campbell A, Citeno J, et al., "Gas turbine in alternative fuel applications: biodiesel field test," in ASME Turbo Expo 2007: Power for land, sea, and air, Montreal, Canada, 2007, pp. Paper no. GT200727212 pp. 397-406.

[21] Purcher G, Allan W, LaViolette M, and Poitras P, Emissions from a gas turbine sector rig operated with synthetic aviation and biodiesel fuel, J. Eng. Gas Turbines and Power 2011; 133:111502-1-11502-8

[22] Timko MT, Herndon SC, Rosa Blanco Edl, Wood EC, Yu Z, Miake-Lye RC, et al., Combustion products of petroleum jet fuel, a Fisher-Trospch synthetic fuel, and a biomass fatty acid methyl ester fuel for a gas turbine engine, Combust. Sci. Tech. 2015; 183:1039-1068. 
[23] Corporan E, Reich R, Monroig O, DeWitt MJ, Larson V, Aulich T, et al., Impacts of biodiesel on pollutants emissions of a JP-8-fueled turbine engine, J. Air \& Waste Manage. Assoc. 2005; 55:940-949.

[24] Tangirala V, Chen RH, and Driscoll JF, Effect of heat release and swirl on the recirculatioin within swirl-stabilized flames, Combustion science and technology 1987; 51:75-95.

[25] Gopinath A, Puhan S, and Nagarajan G, Relating the cetane number of biodiesel fuels to their fatty acid composition: a critical study, Proc. of the Inst. of Mech. Eng., Part D: J. Automobile Eng. 2009; 223:565-583.

[26] Farrell JT, Cernansky NP, Dryer FL, Friend DG, Hergart CA, Law CK, et al., "Development of an Experimental Database and Kinetic Models for Surrogate Diesel Fuels," in SAE Paper 2007-01-0201, 2007 SAE World Congress, 2007, pp. 16-19 April 2007.

[27] Graboski MS and McCormick RL, Combustion of fat and vegetable oil derived fuels in diesel engines, Progress in Energy and Combustion Science 1998; 24:125-164.

[28] Pratas MG, Freitas SVD, Oliveira MB, Monteiro SC, Lima AS, and Coutinho JAP, BIodiesel density: Experimental Measurements and Prediction Models, Energy and Fuels 2011; 25:2333-2340.

[29] Chong CT and Hochgreb S, Effect of Atomizing Air Flow on Spray Atomization of an Internal Mix Twin-fluid Atomizer, Atom Sprays 2015; 25:657-673.

[30] Hardalupas Y and Orain M, Local measurements of the time-dependent heat release rate and equivalence ratio using chemiluminescent emission from a flame, Combust. Flame 2004; 139:188-207.

[31] Song J, Alam M, Boehman AL, and Kim U, Examination of the oxidation behaviour of biodiesel soot, Combustion and Flame 2006; 146:589-604.

[32] Zhang J, Jing W, Roberts WL, and Fang T, Effects of ambient oxygen concentration on biodiesel and diesel spray combustion under simulated engine conditions, Energy 2013; 57:722-732.

[33] Marchione T, Allouis C, Amoresano A, and Beretta F, Experimental Investigation of a pressure swirl atomizer spray, J. Prop Power 2007; 23:1096-1101 .

[34] Lefebvre AH, Airblast atomization, Prog. Energy Combust. Sci. 1980; 6:233-261. 


\section{Figure captions}

Figure 1: (a) Schematic of the swirl flame burner and flow delivery system and (b) axial swirler placed at burner outlet. Dimensions are in millimetre.

Figure 2: Gas chromatograph elution profile for (a) diesel and (b) RME

Figure 3: Abel transformed (a-c) $\mathrm{CH}^{*}$ chemiluminescence images and (d-f) intensity profiles for diesel, 50\% RME/diesel blend and RME flames.

Figure 4: Abel transformed (a-c) long bandpass images and (d-f) intensity profiles for diesel, 50\% RME/diesel blend and RME flames.

Figure 5: Flame emission spectral measurements of diesel, RME and 50\% RME/diesel blend flames. The spectra of RME and 50\% RME/diesel blends are displaced along the wavelength axis by +10 and $+20 \mathrm{~nm}$ respectively for clarity.

Figure 6: Droplet number density $(\mathrm{a}, \mathrm{b}, \mathrm{c})$ and volume flux $(\mathrm{d}, \mathrm{e}, \mathrm{f})$ profiles at axial locations 10 , 15 and $20 \mathrm{~mm}$ from burner outlet under the power output of $6 \mathrm{~kW}$. Note the different scales on each figure.

Figure 7: Droplet axial velocity (a,b,c) and SMD profiles (d,e,f) for diesel, RME and 50\% $\mathrm{RME} /$ diesel blend flames established under constant power output of $6 \mathrm{~kW}$ for three different heights from the burner face. 
Figure 8: Droplet mean axial velocity as a function of droplet SMD for (a) diesel and (b) RME reacting sprays.

Figure 9: The emissions indices of $\mathrm{NO}, \mathrm{NO}_{2}$ and $\mathrm{CO}$ expressed in per unit $\mathrm{kg}$ of fuel (left) and per unit $\mathrm{kWh}$ (right) as a function of excess air ratio under the same power output of $6 \mathrm{~kW}$ for diesel, RME and 50\% RME/diesel blend.

Figure 10: The emissions indices of $\mathrm{NO}, \mathrm{NO}_{2}$ and $\mathrm{CO}$ expressed in per unit $\mathrm{kg}$ of fuel (left) and per unit $\mathrm{kWh}$ (right) as a function of atomizing air-to-liquid mass ratio through the injector under the same power output of $6 \mathrm{~kW}$, at fixed global AFR by varying the main air flow rate.

\section{Table captions}

Table 1: Geometry of axial swirl flame burner

Table 2: Fuel properties

Table 3: Operating conditions. Global power $6 \mathrm{~kW}$ at $\phi=0.47$.

Table 4: PDA operational parameters 

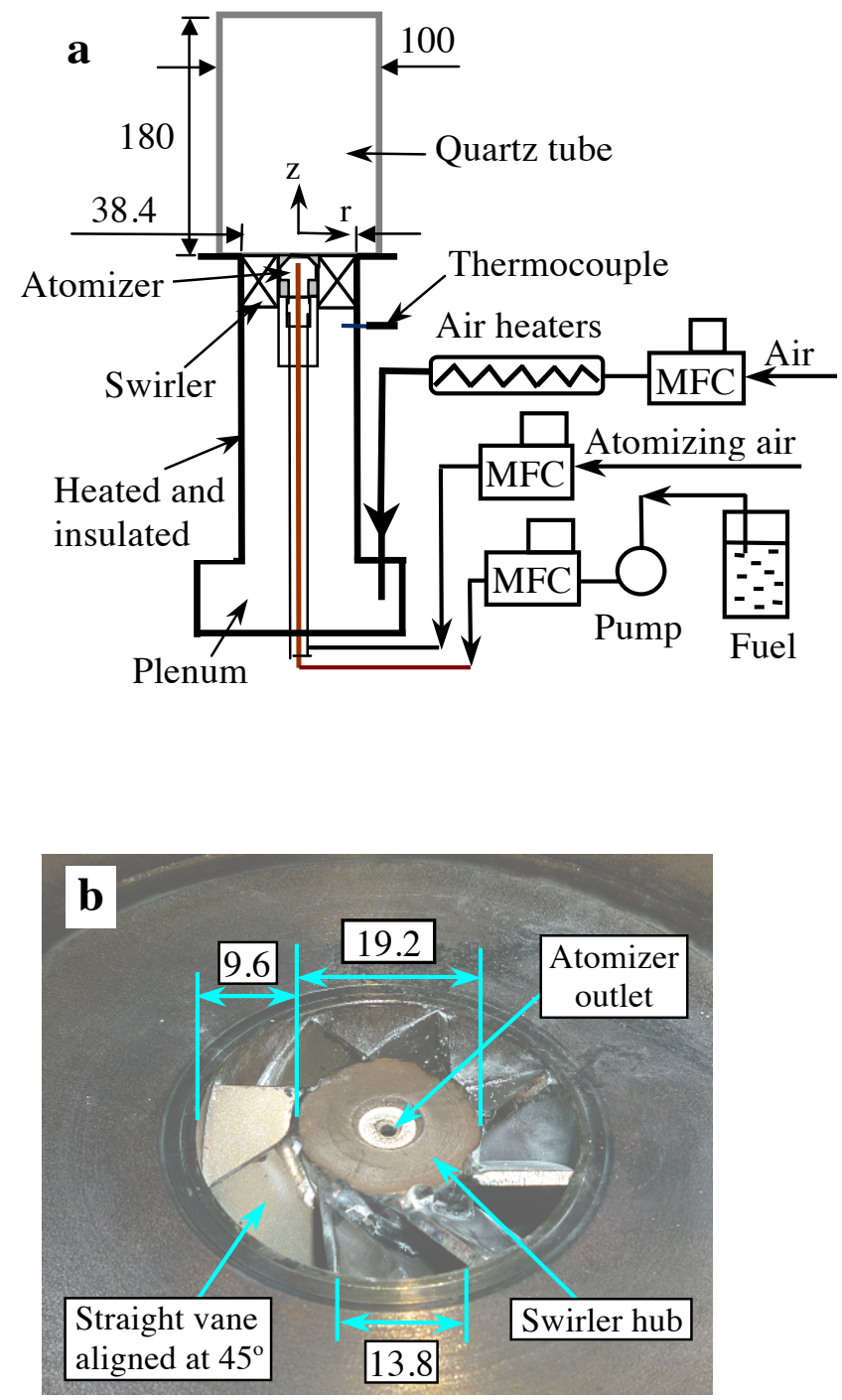

Figure 1 

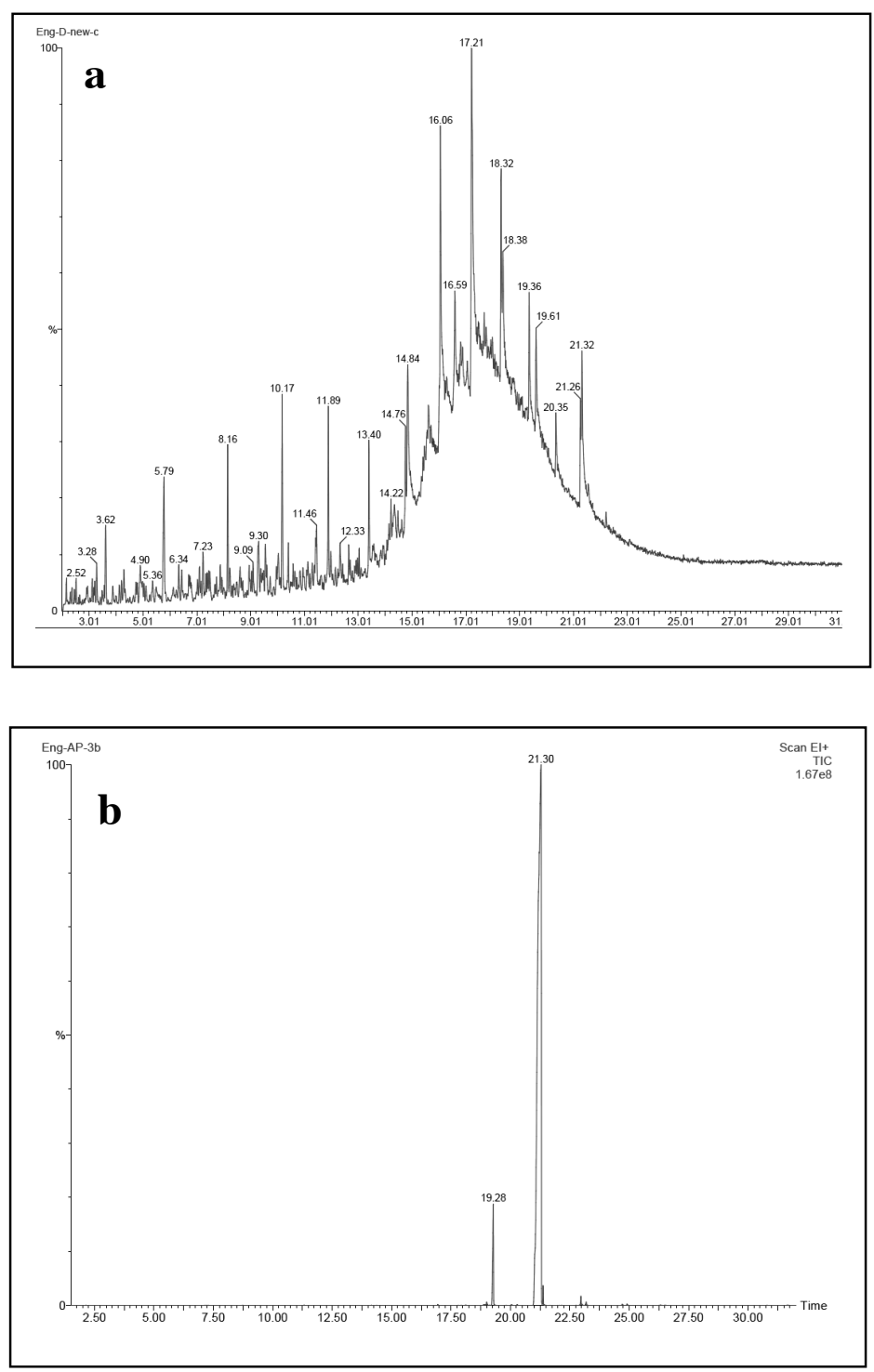

Figure 2 


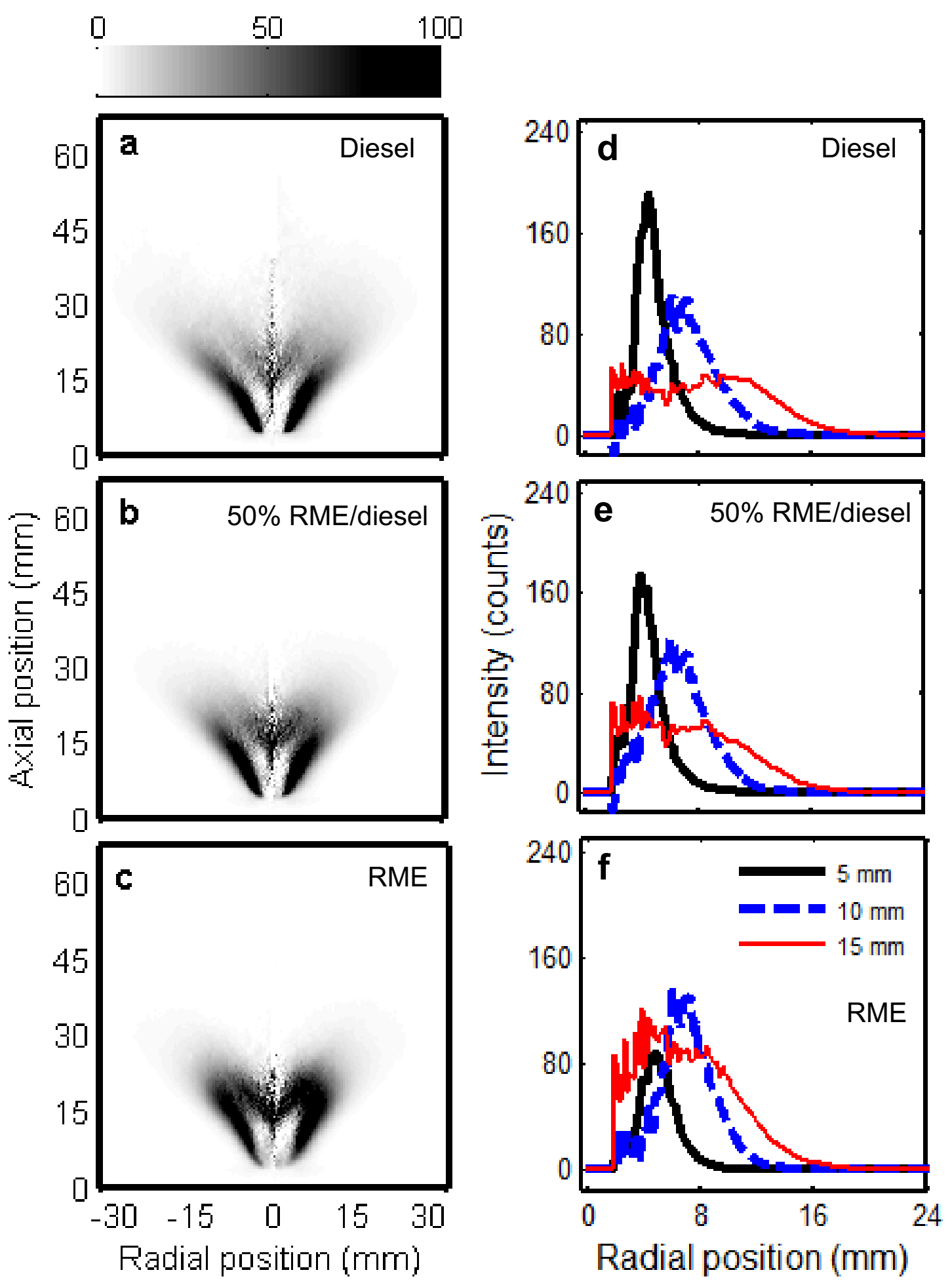

Figure 3 

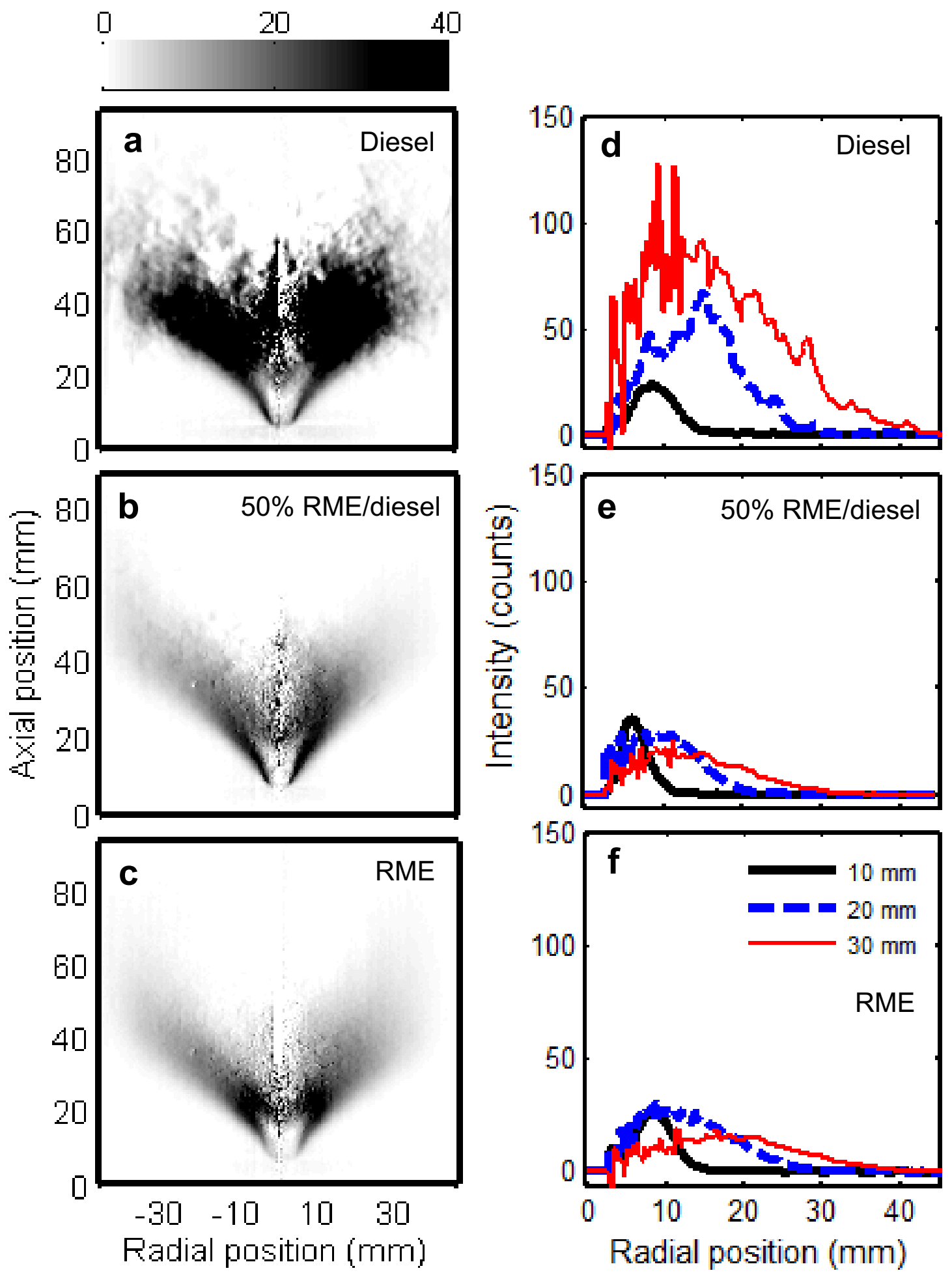

Figure 4 


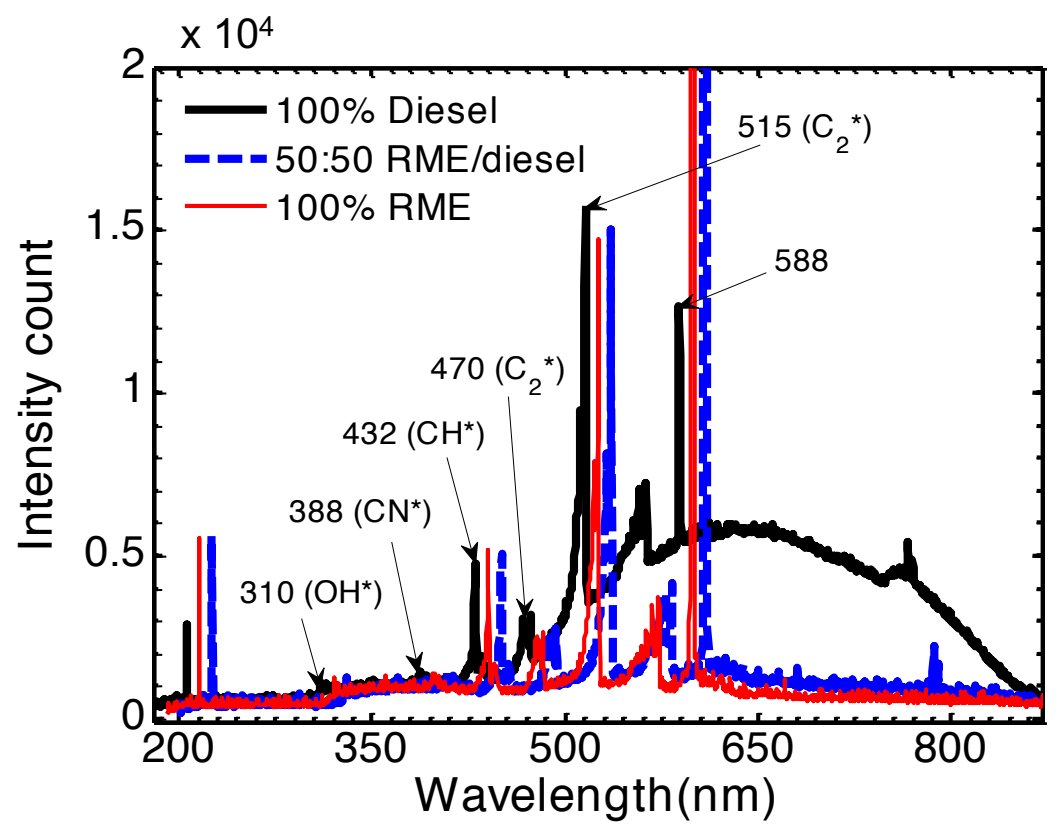

Figure 5 


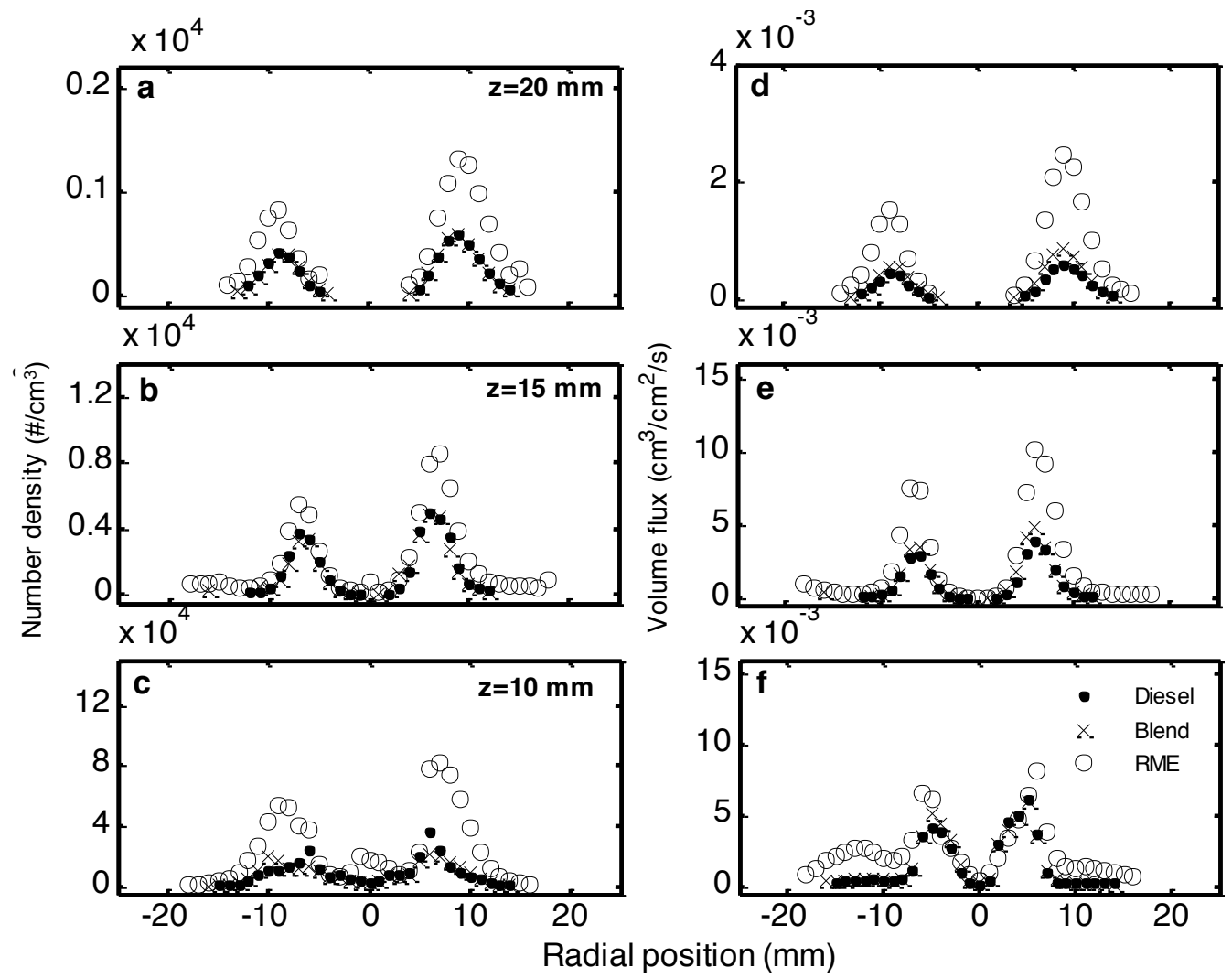

Figure 6 

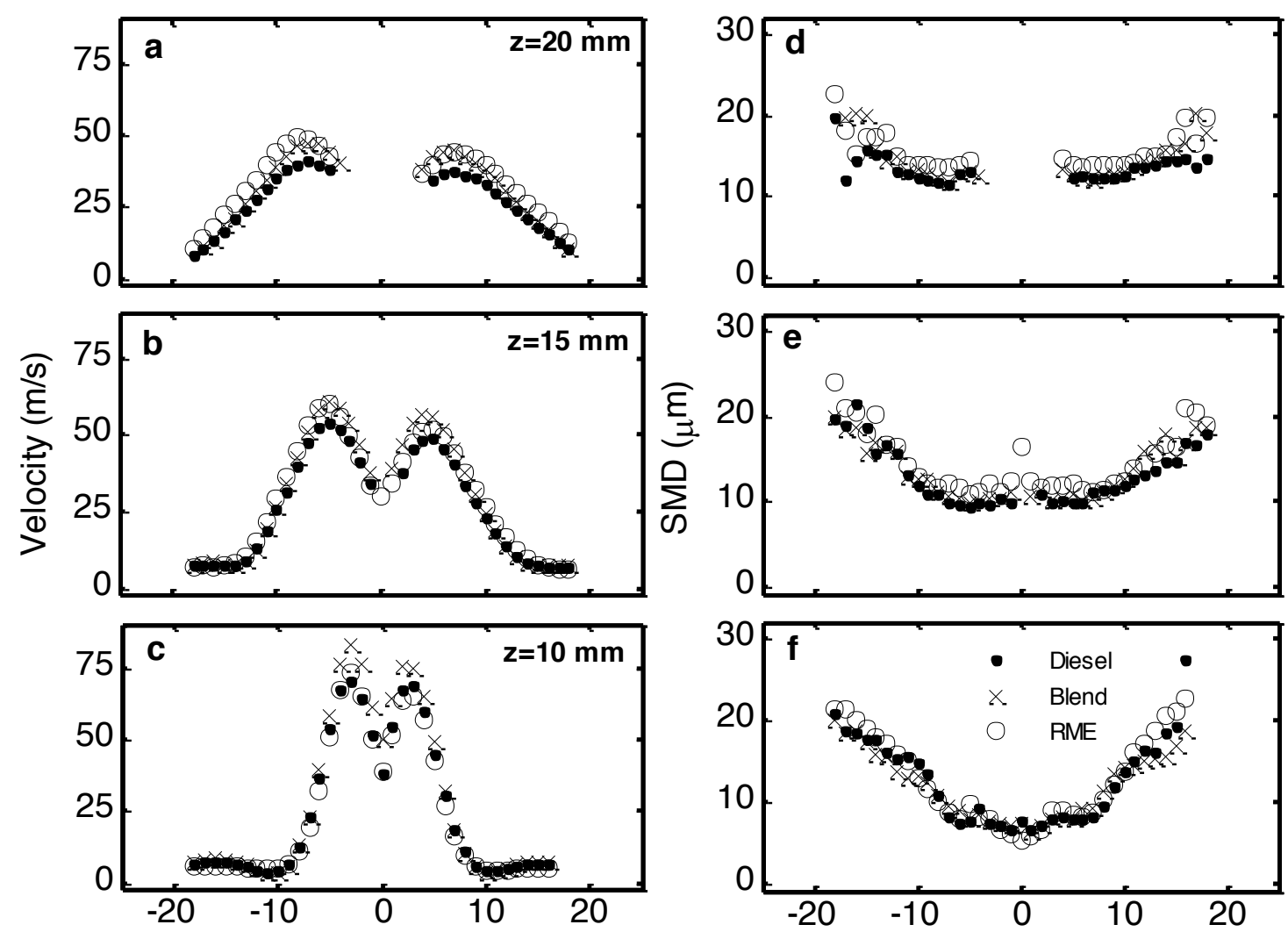

Radial position (mm)

Figure 7 


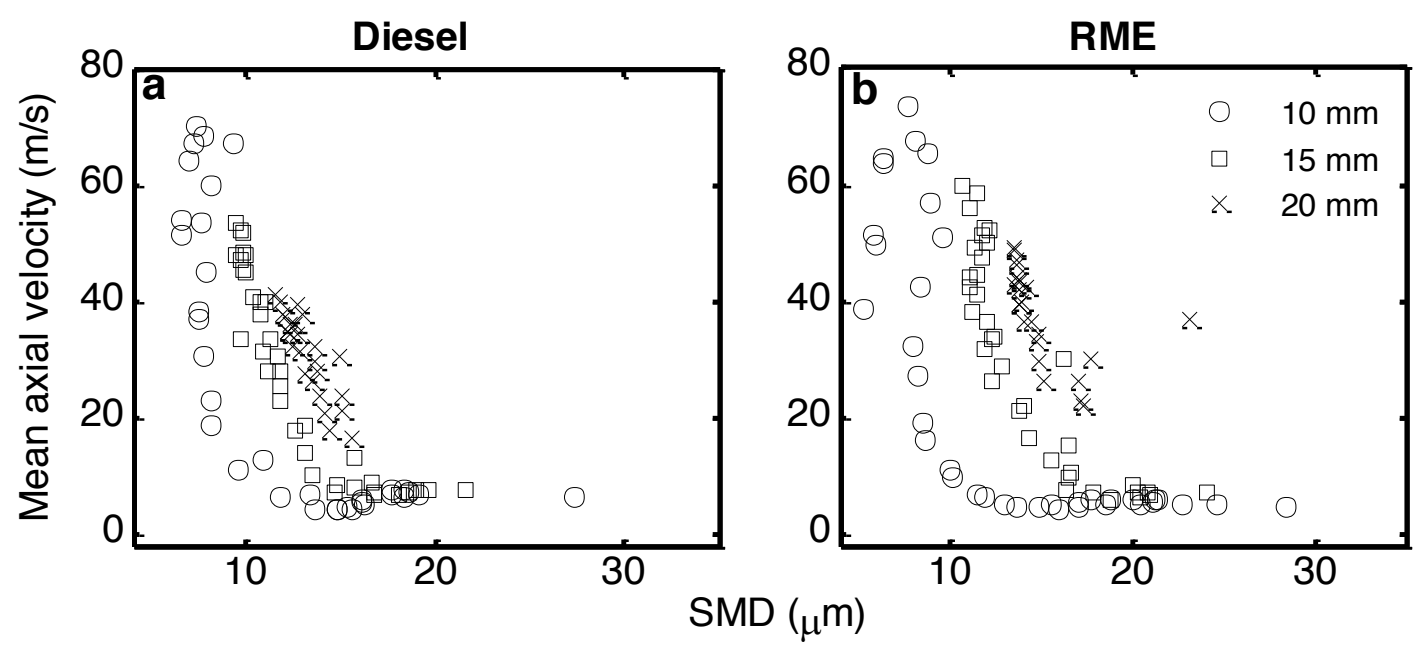

Figure 8 

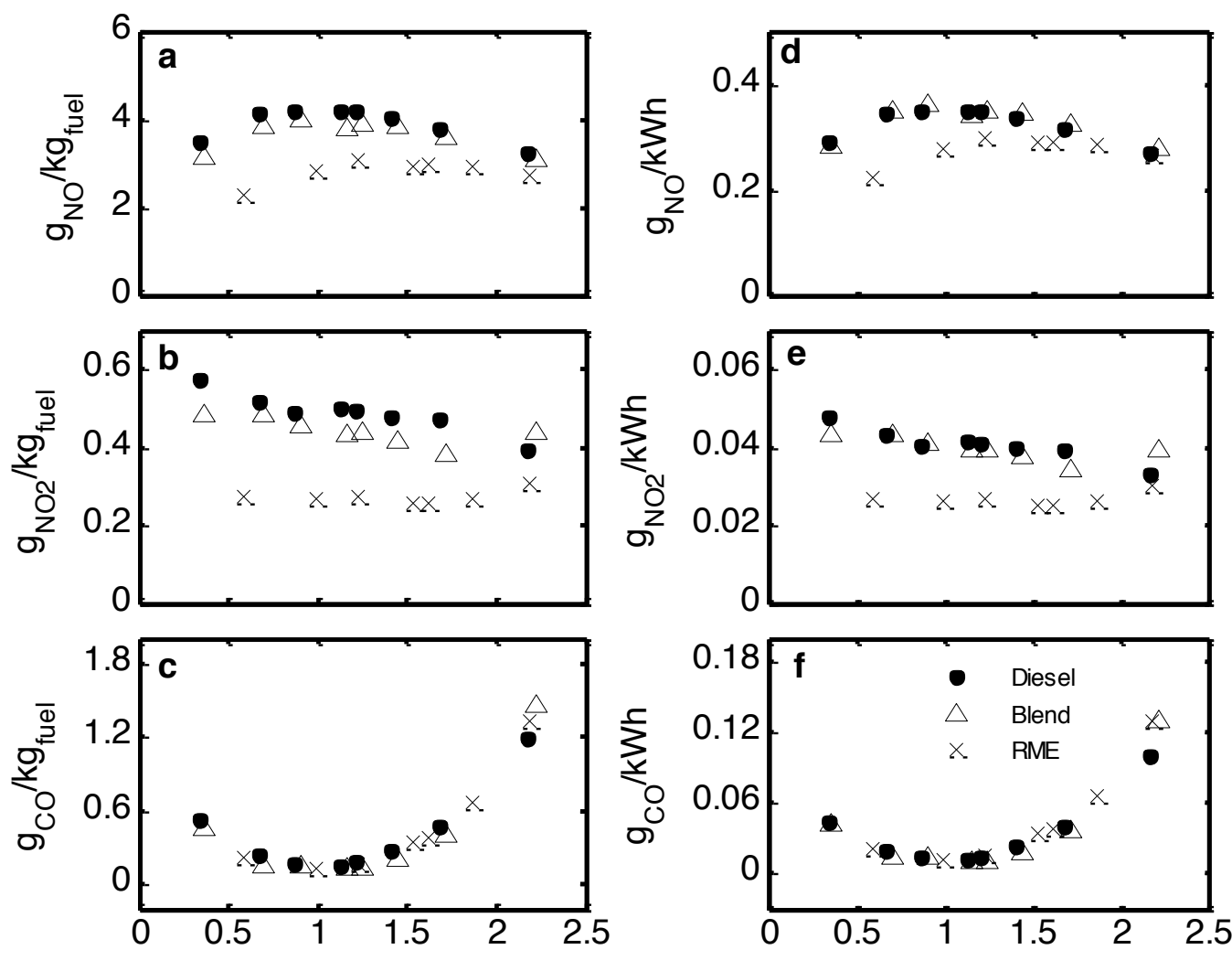

Excess air ratio $\lambda$

Figure 9 

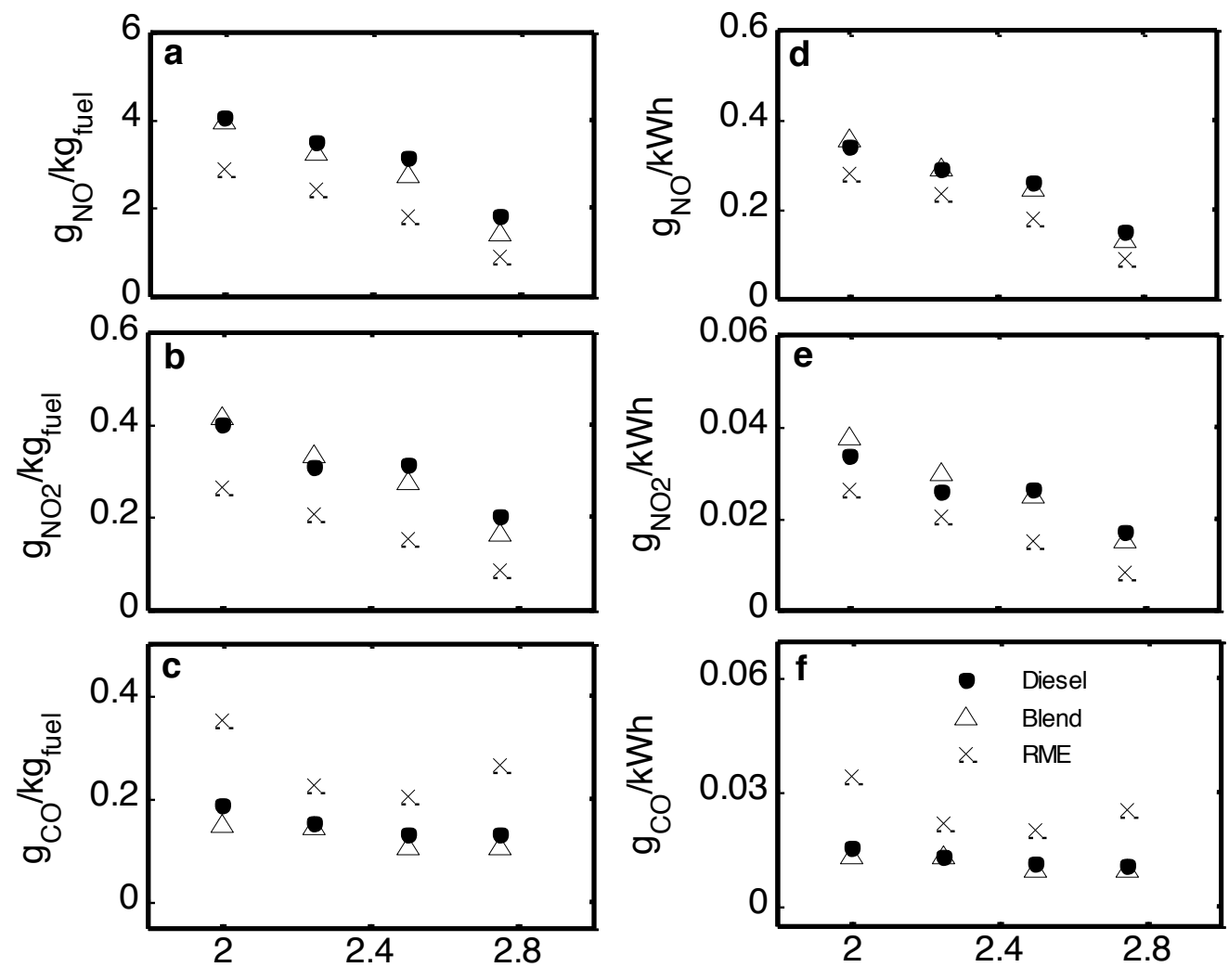

Atomizing air-to-liquid ratio (ALR)

Figure 10 
Table 1: Geometry of axial swirl flame burner

\begin{tabular}{|c|c|}
\hline \multicolumn{2}{|l|}{ Atomizer } \\
\hline Material & Stainless steel \\
\hline Type & Airblast \\
\hline Manufacturer & Delavan \\
\hline Model & SN type-30610-1 \\
\hline Atomizing air orifice, $d_{a}(\mathrm{~mm})$ & 1.73 \\
\hline Fuel orifice, $d_{f}(\mathrm{~mm})$ & 0.5 \\
\hline \multicolumn{2}{|l|}{ Air swirler } \\
\hline Material & Stainless steel \\
\hline Type & Axial, straight vane \\
\hline Swirl number, $S_{N}$ & 0.78 \\
\hline Swirl angle, $\theta\left(^{\circ}\right)$ & 45 \\
\hline Number of blades & 8 \\
\hline Blade thickness, $t(\mathrm{~mm})$ & 1.5 \\
\hline \multicolumn{2}{|c|}{ Burner wall } \\
\hline Material & Quartz \\
\hline Burner outlet diameter, $D(\mathrm{~mm})$ & 100 \\
\hline Burner wall length, $L(\mathrm{~mm})$ & 180 \\
\hline \multicolumn{2}{|c|}{ Burner outlet geometry } \\
\hline Swirl hub diameter, $D_{h}(\mathrm{~mm})$ & 19.2 \\
\hline Burner outlet diameter, $D_{o}(\mathrm{~mm})$ & 38.4 \\
\hline Effective burner outlet area, $A_{e f f}\left(\mathrm{~mm}^{2}\right)$ & 652.8 \\
\hline Blockage ratio & 0.45 \\
\hline
\end{tabular}


Table 2: Fuel properties

\begin{tabular}{|c|c|c|}
\hline Properties & Diesel $[5,27]$ & RME [25] \\
\hline Supplier & Shell & ADM \\
\hline Approx. formula & $\mathrm{C}_{16} \mathrm{H}_{34}$ & $\mathrm{C}_{19} \mathrm{H}_{36} \mathrm{O}_{2}$ \\
\hline $\mathrm{H} / \mathrm{C}$ ratio* & 1.9 & 1.89 \\
\hline $\mathrm{C} / \mathrm{O}$ ratio* & - & 10.06 \\
\hline Spec. gravity at $15^{\circ} \mathrm{C}$ & 0.85 & 0.88 \\
\hline Viscosity at $40^{\circ} \mathrm{C}(\mathrm{cSt})$ & 2.6 & 4.83 \\
\hline Cetane number & 52 & 51 \\
\hline Lower heating value (LHV) $(\mathrm{kJ} / \mathrm{kg})$ & 43090 & 36800 \\
\hline
\end{tabular}

*Laboratory analysis 
Table 3: Operating conditions. Global power $6 \mathrm{~kW}$ at $\phi=0.47$.

\begin{tabular}{cccc}
\hline Fuel & Main air $(\mathbf{g} / \mathbf{s})$ & Atomizing air $(\mathbf{g} / \mathbf{s})$ & Fuel $(\mathbf{g} / \mathbf{s})$ \\
\hline Diesel & 4.15 & 0.28 & 0.14 \\
RME & 4.04 & 0.32 & 0.16 \\
$50 \%$ RME/diesel & 3.96 & 0.30 & 0.15 \\
\hline
\end{tabular}


Table 4: PDA operational parameters

\begin{tabular}{ll}
\hline \multicolumn{1}{c}{ Transmitting optics } \\
\hline Wavelength (nm) & 514.5 \\
Power (W) & 0.8 \\
Beam spacing (mm) & 45 \\
Beam width (mm) & 2.2 \\
Focal Length (mm) & 500 \\
\hline \multicolumn{1}{c}{ Receiving Optics } \\
\hline Focal length (mm) \\
Scattering angle $\left.{ }^{\circ}\right)$ & 310 \\
\hline \multicolumn{1}{c}{ Measurement volume } \\
\hline Number of fringes & 56 \\
Width of measurement volume (mm) & 26 \\
Length of measurement volume (mm) & 0.15 \\
\hline
\end{tabular}

